\title{
Molecular targets of selenium in prostate cancer prevention (Review)
}

\author{
RIZKY ABDULAH $^{1,2}$, KENJI KOBAYASHI ${ }^{2}, \mathrm{CHIHO} \mathrm{YAMAZAKI}^{2}$ and HIROSHI KOYAMA ${ }^{2}$ \\ ${ }^{1}$ Faculty of Pharmacy, Universitas Padjadjaran, Jatinangor, Indonesia; \\ ${ }^{2}$ Department of Public Health, Gunma University Graduate School of Medicine, Gunma, Japan
}

Received January 24, 2011; Accepted March 30, 2011

DOI: 10.3892/ijo.2011.1035

\begin{abstract}
Prostate cancer is one of the leading causes of cancer-related deaths among males. Although use of the micronutrient selenium in prostate cancer clinical trials is limited, the outcomes indicate that selenium is a promising treatment. Furthermore, selenium inhibits prostate cancer through multiple mechanisms, and it is beneficial in controlling the development of this disease. This review highlights the latest epidemiological and biomolecular research on selenium in prostate cancer, as well as its prospects for future clinical use.
\end{abstract}

\section{Contents}

1. Introduction

2. Epidemiology

3. The mechanism of selenium in prostate cancer

4. Conclusions and future challenges

\section{Introduction}

Cancer is a devastating disease and currently is the cause of more than 7 million deaths worldwide each year. Cancer is the uncontrolled growth and spread of cells, and it can affect almost any tissue in the body (1). Among all cancers, prostate cancer is the fifth most common (2), and the second most common cancer in men worldwide (2-4).

The worldwide geographical distribution of prostate cancer varies. Rates are lower in Asian countries and much higher in North America, Australia and Europe. In 2002, the incidence per 100,000 individuals in China was 75- and 50-fold lower than the incidence in North America and Australia, respectively (2). In American men, prostate cancer is the most common

Correspondence to: Dr Rizky Abdulah, Division of Pharmacology and Clinical Pharmacy, Faculty of Pharmacy, Universitas Padjadjaran, Jl. Raya Bandung Sumedang Km.21, Jatinangor 45363, Indonesia E-mail: abdulahrizky@gmail.com

Key words: selenium, prostate cancer, apoptosis, cell cycle cancer, with an estimated 218,890 new cases and 27,050 deaths in 2007 (5).

This distribution may be correlated with racial differences, which is believed to play a role in prostate cancer development $(6,7)$. The highest prevalence of prostate cancer is in the African-American population, whereas there is a much lower risk in Asian populations (8). However, recent publications have reported that in Asian countries, prostate cancer incidence has rapidly increased in the last three decades $(9,10)$.

Due to this high incidence, the identification of a compound that may inhibit cancer development is becoming an important objective for scientists. Currently, hundreds of chemicals have been and are being evaluated for their anticancer activity. Among them, selenium has been reported to be successful in epidemiological, in vitro and in vivo experiments, including experiments with prostate cancer. In this review, we discuss the recent developments in selenium research as both an alternative and combination treatment option in the management of prostate cancer.

\section{Epidemiology}

The promising effects of selenium against prostate cancer were triggered by the findings of Clark and co-workers in 1996, who reported a strong inverse association between selenium and prostate cancer after the supplementation of free-living people with selenized brewer's yeast for a mean of 4.5 years. They reported a $63 \%$ reduced risk in prostate cancer among subjects taking selenium supplements (11). This result was supported by a later study in 2005 that found that selenium supplementation combined with vitamin $E$ induced proteomic changes that were associated with a prostate cancer-free status (12). In 2006, Sabichi and co-workers conducted a randomized, controlled, short-term trial of selenomethionine supplementation and reported that selenium taken as an oral supplement accumulates preferentially in the prostate gland which may contribute to its anticancer effects (13).

Blood and toenail selenium status has also been associated with prostate cancer incidence. Several studies have reported an inverse correlation between blood selenium levels and prostate cancer and have suggested that selenium may reduce the risk of prostate cancer (14-16). Similar reports have been published based on measurements of toenail selenium $(17,18)$, a well-accepted biomarker of long-term selenium status $(19,20)$. 


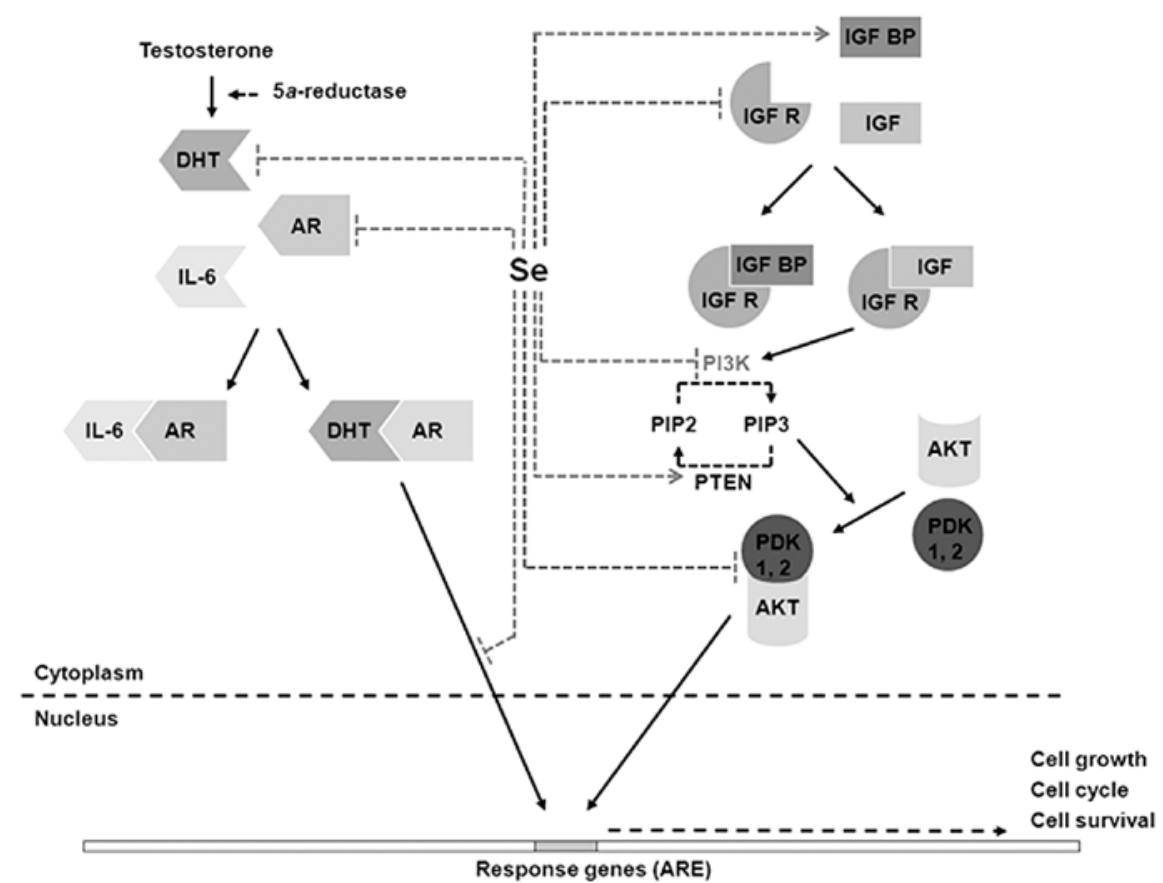

Figure 1. Reported mechanisms of how selenium (Se) inhibits the androgen receptor and PI3K/Akt signaling.

Aside from these results, however, conflicting results have also been reported. Studies in the UK and the US suggested that there was no strong association between nail and serum selenium and prostate cancer risk (21-23). A recent SELECT study (selenium and vitamin E cancer prevention), the largest cancer chemoprevention trial ever conducted, is a long-awaited randomized placebo-controlled trial study that involved 35,533 men in North America; the study showed that selenium or vitamin $\mathrm{E}$ alone or in combination did not lower prostate cancer incidence (24). In this study, selenium was supplemented in the form of selenomethionine, which is the major selenium compound in selenized yeast, the material used in Clark's study (11). Notably, the result was predicted by Drake (25) based on a lack of the enzyme required to convert selenomethionine to its active form, methylselenol, in humans. Moreover, a later analytical study reported that the selenomethionine distribution in the supplement used in Clark's study accounted for only $27 \%$ of the total selenium (26). Thus, it is possible that the effect of selenium in Clark's supplementation study was not caused by selenomethionine, but rather by other selenium compounds or the combination of selenium-containing compounds in the yeast $(26,27)$. Therefore, the negative results of the SELECT study do not discredit any preventive properties of selenium against prostate cancer. Indeed, from three metaanalysis studies on articles that examined the association between selenium and prostate cancer, all suggested that selenium intake may reduce the risk of prostate cancer $(4,28,29)$.

\section{The mechanism of selenium in prostate cancer}

\section{Signaling pathways}

Androgen receptor signaling. Androgen receptor (AR) signaling is one of the key factors in prostate cancer development and progression. AR is a transcription factor of the nuclear receptor family (30) that mediates androgen by activating the androgen response element (ARE) (31).

Testosterone becomes an active androgen after conversion into dihydrotestosterone (DHT) by the enzyme $5 \alpha$-reductase (32). Active androgen then binds with AR, leading to its nuclear translocation and interactions with AREs to activate androgenresponsive gene transcription $(31,32)$. Aside from active androgen, AR signaling was also found to be induced by interleukin (IL)-6 and oncostatin $\mathrm{M}$ in in vitro experiments $(33,34)$.

Several selenium compounds are known to disrupt AR signaling in prostate cancer cells. In in vitro experiments using human prostate cancer cells, methylseleninic acid (MSeA), a methylselenol precursor, was reported to reduce androgen signaling at multiple stages by increasing AR protein degradation at both the mRNA and protein levels and by reducing AR nuclear translocation (35-37). Furthermore, MSeA also reduced AR-mediated gene expression, including prostatespecific antigen (PSA) expression (35-39). Another methylselenol precursor, selenomethionine (SeMet), was found to decrease AR activity in the LNCaP human prostate cancer cell line (40). Additionally, Se-methylselenocysteine (Se-MSC) significantly inhibited LNCaP tumor growth in LNCaP-induced mice by decreasing AR expression in tumor tissues and serum PSA levels (41).

Selenite, an inorganic form of selenium, has also been reported to disrupt AR signaling. Husbeck and co-workers (39) found that selenite inhibited AR signaling by decreasing AR expression and activity through a redox mechanism. Moreover, unlike MSeA, selenite also inhibited IL-6-mediated AR signaling in the LNCaP human prostate cancer cell line (42). Taken together, as summarized in Fig. 1, these reports describe a potential role of selenium in the disruption of AR signaling in prostate cancer. 
Insulin-like growth factor signaling. Insulin-like growth factor (IGF) signaling involves IGF ligands (IGF-I and IGF-II), IGF receptors (IGF-IR and IGF-IIR) and IGF binding protein (IGFBP) (43). IGFBP-3 is the binding protein that regulates IGF (44). Once released from IGFBP-3, IGF activates the IGF receptor to induce downstream signaling cascades, thereby controlling cell proliferation and cell survival (43). The ability of the IGF receptor to induce downstream signaling cascades comes from IGF-IR. Upon binding with IGF-I, IGF-IR induces downstream signaling via Ras/Raf/mitogen-activated protein kinase (MAPK) and/or phosphatidylinositol 3-kinase (PI3K)/ Akt (43-46). However, IGF-IIR bound with IGF-II still lacks tyrosine kinase activity and does not transduce signals (47), so its precise function in tumorigenesis and tumor growth is still unclear (48). IGF-I is a mitogenic ligand that is overexpressed in prostate cancer and is associated with prostate cancer risk $(49,50)$; therefore, down-regulation of IGF-IR signaling may be a promising target for the chemoprevention of prostate cancer.

Schlicht and co-workers (51) identified 154 genes that showed similar levels of differential expression upon SeMet treatment in the human PC-3 and rat PAII prostate cancer cell lines. Their analysis and data mining showed that IGFBP-3 was up-regulated by SeMet in both cell lines. Moreover, SeMet and MSeA have also been reported to down-regulate IGF-IR gene expression in LNCaP cells (52). Although further research is still needed, their findings suggest that restoration of IGFBP-3 by selenium may inhibit prostate tumorigenesis by disrupting the IGF-IR signaling pathway.

Toll-like receptor signaling. Toll-like receptors (TLR) have gained interest in recent years since being identified as one of the important mediators of inflammation. Furthermore, they are able to recognize many microbial pathogens with various adaptor proteins and activate different transcription factors. Activation of TLR-dependent signaling leads to activation of the immune response, as well as the expression and release of various cytokines and associated molecules (53). Recent studies have shown that sequence variations in the TLR4 gene and TLR6-TLR1-TLR10 gene cluster are associated with prostate cancer risk (54-56). However, the functional role of TLR variants in the growth and development of prostate cancer remains to be established (57).

There are limited reports on the ability of selenium compounds to affect the TLR signaling pathway, especially in prostate cancer. However, MSeA has been reported to up-regulate TLR2 gene expression in PC-3 cells (58). TLR2 is known as the death receptor in apoptosis (59). Up-regulation of TLR2 stimulates apoptosis through adaptor molecules via a pathway that involves caspase-8 (59). This report may lead to additional details on the role of selenium and TLR signaling in prostate cancer chemoprevention.

Phosphatidylinositol 3-kinase (PI3K)/Akt signaling. Up-regulation of PI3K/Akt is important for the growth of many types of cancers, including prostate cancer. PI3K converts phosphatidylinositol-4,5-biphosphate (PIP2) to phosphatidylinositol-3,4,5-triphosphate (PIP3), which recruits phosphoinositide-dependent kinase 1 (PDK1) and Akt to the cell membrane. This recruitment partially activates Akt by phosphorylation at Thr308 by PDK1. Full activation of Akt occurs after a second phosphorylation by another kinase at Ser473. It is still unclear which kinase is responsible for Ser473 phosphorylation; however, several kinases have been reported to play an important role in this event, including integrin-linked kinase (ILK), MAPKAP kinase and rictormTOR kinase. Through its downstream actions, Akt activation mediates cancer cell proliferation, motility, survival and angiogenesis. Phosphatase and tensin homologue (PTEN) is known to negatively regulate PI3K/Akt signaling by blocking the conversion of PIP2 to PIP3. However, in cancer cells, PTEN is either absent or nonfunctional, resulting in a high level of PIP3 and hyperactivation of Akt (60).

As reported by $\mathrm{Wu}$ and coworkers (61), in PC-3 cells, MSeA is capable of reducing the activity of PI3K by $30 \%$, which leads to a decrease in Akt and PDK1 membrane localization. Furthermore, MSeA inhibits Akt phosphorylation at both Thr308 and Ser473 (61) and up-regulates PTEN gene expression in PC-3 cells (58). In DU-145 cells, Berggren and co-workers found increased PTEN activity and decreased Akt phosphorylation at Ser473 after the cells were treated with selenite (62). Inhibition of Akt phosphorylation at Ser473 in DU-145 cells was also reported after the cells were treated with MSeA $(63,64)$ and SeMet $(64)$.

We recently reported that the addition of selenium to broccoli sprouts, which generates Se-MSC as the major selenium compound, induces the down-regulation of phosphorylated Akt and downstream phosphorylated mTOR in LNCaP cells (65). As expected, this down-regulation was not noted in $\mathrm{LNCaP}$ cells treated with normal broccoli sprout extract that contained only sulforaphane as the active anticancer agent. In recent years, the PI3K/Akt signaling pathway has been shown to play a major role in cancer development and survival. Thus, as shown for selenium in Fig. 1, the PI3K/Akt pathway may be a fruitful target for cancer therapy.

\section{Cell cycle pathway}

Cyclins, cyclin-dependent kinases $(C D K s)$ and $C D K$ inhibitors $(C K I s)$. Interactions between cyclins, CDKs and CKIs are known to play critical roles in the cell cycle. Among the CDKs, CDK2, CDK4, CDK6 and CDK1 are the most frequent kinases that are deregulated in prostate cancer (57). CDKs can be activated by association with cyclin, by phosphorylation of its T-loop threonine by CDK-activating kinase and by dephosphorylation of threonine 14 /tyrosine 15 by cdc25 phosphatase (66).

CDK activation by specific cyclins regulates different phases of cell cycle progression and finally induces uncontrolled cell proliferation and survival (67). For example, association of CDK4 and CDK 6 with D-type cyclin accelerates the early and mid-G1-phase progression $(68,69)$, and CDK2 interacting with cyclin E promotes the late G1 and G1-S transition (70-72). CDK2 interacting with cyclin A is responsible for $\mathrm{S}$-phase and early G2 phase progression (73-75), and CDK1 interacting with cyclin B promotes the G2-M transition (76,77).

However, these cyclin-CDK complexes are negatively regulated and controlled through associations with CKIs $(67,78)$. There are two families of CKIs; the first family is the cip/kip family. This family includes p21/cip1, p27/kip1 and p57/kip2 (66). p21/cip1 is known as the universal inhibitor of CDKs because of its ability to be involved in all phases of the 


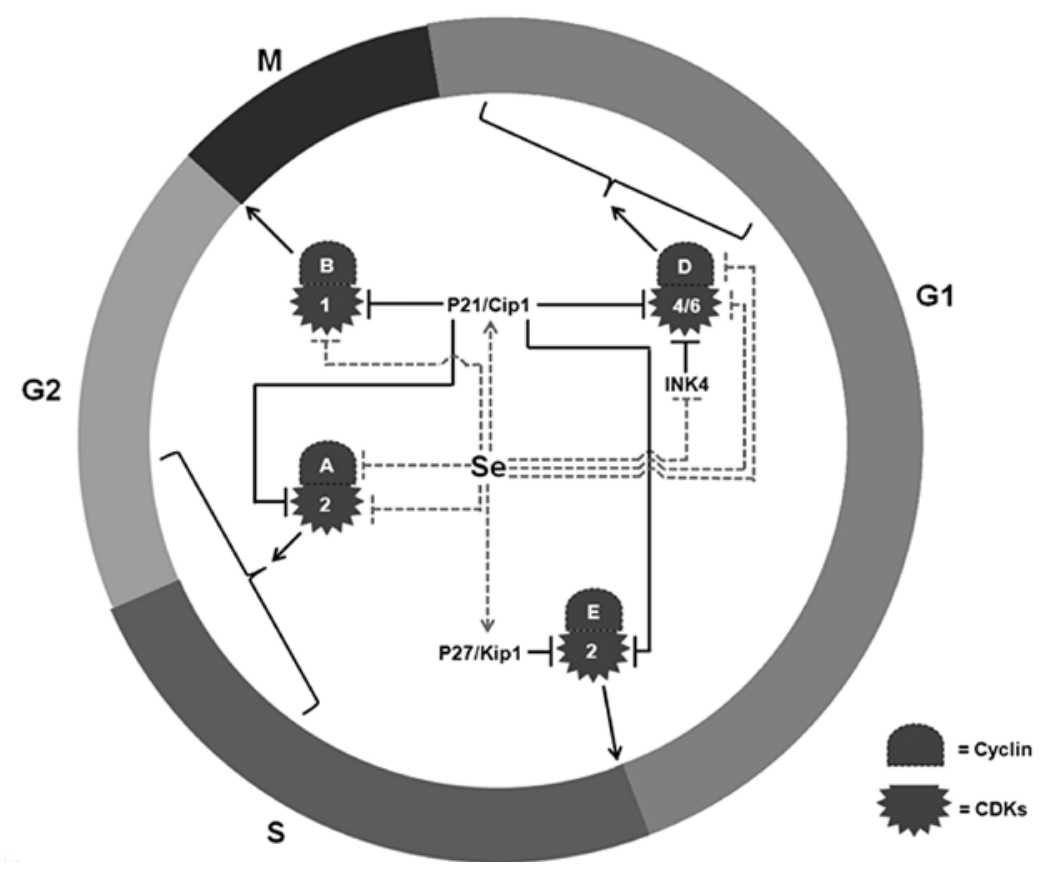

Figure 2. Mechanisms of selenium inhibit prostate cancer cell cycle by altering cyclins, CDKs and CKIs.

cell cycle (79). p27/kip1 is involved in cell cycle regulation during the G1-S transition (80), whereas the specific role of p57/kip2 in cell cycle progression is still poorly understood.

The second family of CKIs is the INK4 family, which includes p15 (INK4b), p16 (INK4a), p18 (INK4c) and p19 (INK4d) (66). This family specifically inhibits CDK4 and CDK6 activity $(81,82)$, thereby inducing $\mathrm{G1}$ arrest in the cell cycle by competing with the cyclin D and CDK4/CDK6 association $(66,82)$. The modulation of cyclin-CDK-CKI association, as shown for selenium in Fig. 2, is promising in prostate cancer treatment.

Chronic treatment with selenite was reported to induce p21 and p27 protein expression followed by G2/M phase arrest in LNCaP cells (83), whereas in DU-145 cells, 24 h of exposure to selenite decreased cyclin D protein expression (63). SeMet has also been shown to induce $\mathrm{G} 2 / \mathrm{M}$ cell cycle arrest by tyrosine phosphorylation of CDK1 in LNCaP, PC-3 and DU-145 cells (84). Moreover, SeMet also down-regulates cyclin D (85) and induces p21 and p27 protein expression in LNCaP cells $(86,87)$.

Studies using MSeA reported a decrease in cdc25 and increases in p19, p21 and p57, followed by G1 phase arrest in LNCaP cells (36). In PC-3 cells, MSeA also decreased cyclin A, CDK1, CDK2 and CDK4, and increased $\mathrm{p} 19$ and $\mathrm{p} 21$ gene expression (58). However, in DU-145 cells, MSeA downregulated cyclin D expression and up-regulated p27 and p21 expression levels (63).

Retinoblastoma-E2F. Another important cell cycle regulator is retinoblastoma $(\mathrm{Rb}) . \mathrm{Rb}$ is a known tumor suppressor that functions by inhibiting the E2F-mediated gene transcription that is required for cell cycle progression (88). Hypophosphorylated $\mathrm{Rb}$ is recognized as an active $\mathrm{Rb}$ because of its ability to sequester E2F family transcription factors. However, phosphorylation of $\mathrm{Rb}$ by CDKs (CDK 4/6-cyclin D or CDK 2-cyclin E) inactivates $\mathrm{Rb}$, thereby releasing E2Fs. Free E2Fs then heterodimerize with their DNA-binding partners leading to transcriptional activation of growth-promoting genes (88-91).

There are three $\mathrm{Rb}$ proteins $(\mathrm{Rb} / \mathrm{p} 110, \mathrm{Rb} 1 / \mathrm{p} 107$ and $\mathrm{Rb} 2 /$ p130) and six E2F families (E2F1-6) that heterodimerize with two DNA-binding partners (DP1 and DP2) to form 12 different DNA-binding transcriptional regulators that are needed for entry from the $\mathrm{G} 0$ to $\mathrm{S}$ phase $(90,92,93)$. Upon entering the $\mathrm{S}$ phase, $\mathrm{Rb}$ is kept inactivated by $\mathrm{CDK} /$ cyclin throughout the remainder of the cell cycle $(94,95)$ until mitosis, when $\mathrm{Rb}$ activity is reset by phosphatase activity (93). High levels of E2F have been observed in cancerous cells (96); therefore, targeting the modulation of $\mathrm{Rb}$ and E2F expression may inhibit cancer cell growth by inhibiting S phase entry (97).

In vitro experiments using MSeA have been shown to modulate $\mathrm{Rb}-\mathrm{E} 2 \mathrm{~F}$ expression by increasing $\mathrm{Rb} 1$ gene expression in PC-3 cells (58). MSeA has also been reported to decrease E2F1 gene expression, followed by G2/M phase arrest in $\mathrm{LNCaP}$ cells $(36,52)$. These findings suggest that the modulation of $\mathrm{Rb}-\mathrm{E} 2 \mathrm{~F}$ expression is one of the potential targets of selenium in its inhibition of prostate cancer growth (Fig. 3).

\section{Apoptotic targets}

Nuclear factor- $\kappa B(N F-\kappa B)$ pathway. NF- $\kappa \mathrm{B}$ is a family of transcription factors consisting of NF- $\mathrm{KB} 1$ (p50/p105), NF- $\mathrm{\kappa B} 2$ (p52/p100), RelA (p65), RelB and c-Rel (98). In its inactivated

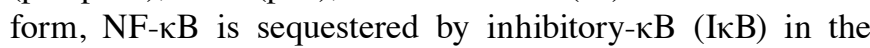
cytoplasm. However, when I $\mathrm{KB}$ is phosphorylated at specific serine sites by I $\kappa B$ kinases (IKKs), NF- $\kappa B$ is free and active. Free NF- $\kappa B$ translocates to the nucleus and binds to the $\kappa B$ sites of a wide spectrum of genes that are involved in cell proliferation, tumor angiogenesis and metastasis (99-101). $\mathrm{NF}-\kappa \mathrm{B}$ is reportedly active in androgen-independent prostate cancer; thus, NF- $\mathrm{kB}$ activation could be a potential target in controlling prostate cancer growth and malignancy. 


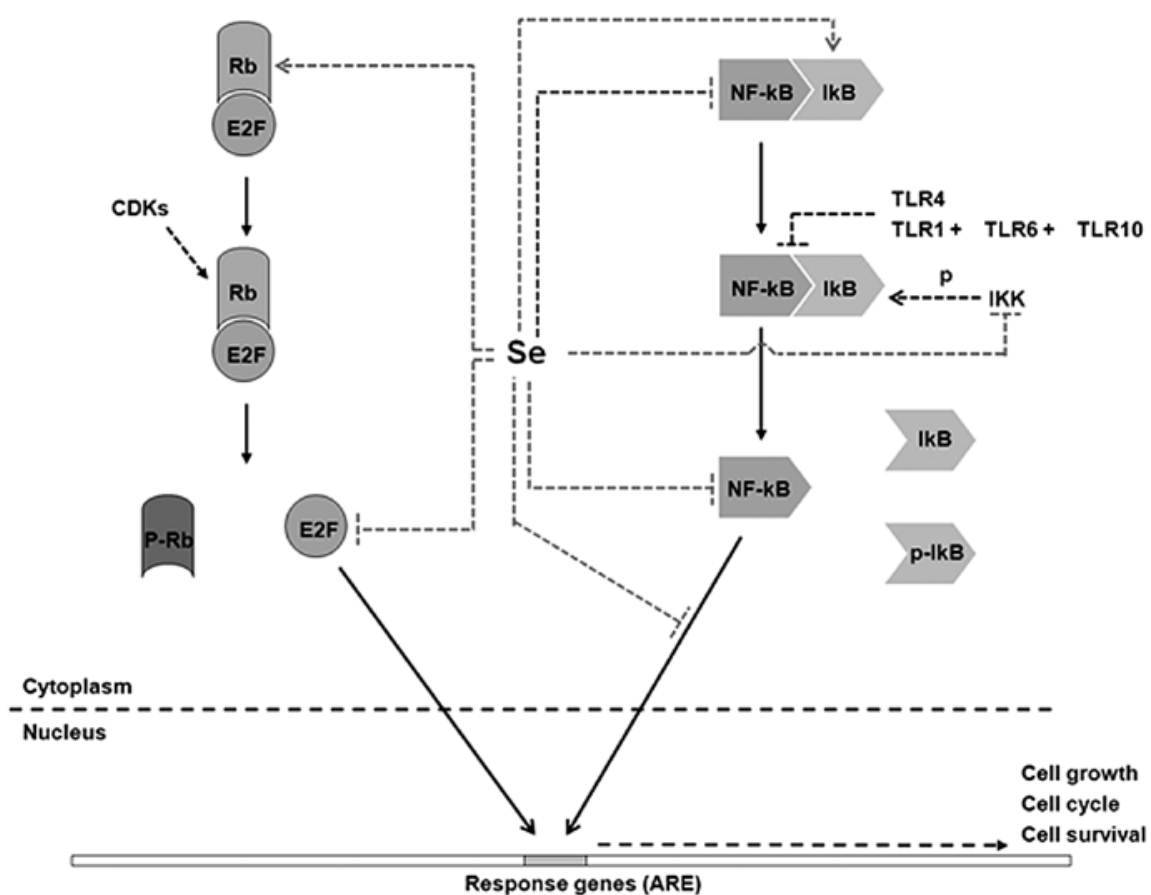

Figure 3. Reported mechanisms of retinoblastoma and NF-кB signaling inhibition by selenium in prostate cancer.

Selenite and MSeA have been reported to inhibit the IKK activity in DU-145 cells, thereby inhibiting the activation of $\mathrm{NF}-\kappa \mathrm{B}$-mediated transcription (102). Using an oligonucleotide array, Dong and co-workers reported that treatment of PC-3 cells with MSeA was able to decrease NF- $\mathrm{kB} 1$ gene expression (58). In LNCaP cells, MSeA is able to prevent the binding of $\mathrm{NF}-\kappa \mathrm{B}$ to its DNA response element, resulting in a reduction in the transcription rates of NF- $\kappa B$-regulated genes (103). Furthermore, Zhao and Brooks found an up-regulation of ІкB and down-regulation of NF- $\mathrm{kB} 2$ gene expression in $\mathrm{LNCaP}$ cells treated with SeMet (52). Taken together, these results showed that selenium compounds may target the NF- $\mathrm{\kappa B}$ activation pathway in prostate cancer growth and malignancy (Fig. 3).

Bcl-2 family proteins. Bcl-2 family proteins are known to play important roles in apoptosis. Based on structural and functional features, they can be divided into three subfamilies: an antiapoptotic protein subfamily that contains the 1-4 homology domains (Bcl-2, Bcl-XL, Bcl-w, Mcl-1, Bfl1 and Bcl-B), a multidomain pro-apoptotic protein subfamily that contains the 1-3 homology domains (Bax, Bak and Bok) and a BH3-only pro-apoptotic protein subfamily that contains only the $\mathrm{BH} 3$ domain (Bim, Bad and Bid) (104).

During mitochondrial apoptosis, cytochrome-c is released from the mitochondria to the cytosol upon stimulation from death stimuli. Cytochrome-c then associates with Apaf-1 and pro-caspase-9 to form the apoptosome, which induces apoptosis through the activation of caspase- 3 and PARP cleavage $(104,105)$. Bcl-2 family proteins regulate this mitochondrial apoptosis by controlling the permeabilization of the mitochondrial membrane. The balance between Bcl-2 family proteins is the key factor determining cell survival or apoptosis. Upon death stimulation, pro-apoptotic bax/bak proteins are activated and mediate pores in the outer mitochondrial membrane that facilitate the release of cytochrome-c, which leads to apoptosis. However, it has been reported that in cancerous cells, the balance of Bcl-2 family proteins is disrupted, and anti-apoptotic Bcl-2 is overexpressed. Overexpression of the anti-apoptotic Bcl-2 protein will block the activation of pro-apoptotic proteins; hence, the cells become resistant to apoptotic death (104-106).

Inorganic selenite has been reported to decrease Bcl-2 expression and increase Bax protein expression in prostate cancer cells lines (LNCaP, DU-145 and LAPC-4) and primary prostate epithelial cell cultures of cancerous subjects. This phenomenon leads to a decrease in the $\mathrm{Bcl}-2$ :Bax ratio, a release of cytochrome-c and the activation of mitochondrial apoptosis (107-111). Furthermore, two methylselenol precursors, MSeA and SeMet, have also been found to decrease the ratio of these pro-apoptotic and anti-apoptotic protein expression levels. MSeA decreased Bcl-2 anti-apoptotic protein levels and increased the Bax, Bak and Bid pro-apoptotic proteins of LNCaP, DU-145 and PC-3 cells (112), while SeMet increased the Bax pro-apoptotic protein levels in LNCaP cells (87). These findings may suggest that the Bcl-2 protein families play key roles in selenium-induced mitochondrial apoptosis.

Inhibitor of apoptosis protein (IAP). IAP proteins consist of nine family members: X-linked IAP, cIAP1, cIAP2, melanoma IAP, IAP-like protein 2, neuronal apoptosis inhibitor protein, livin, appolon and survivin $(113,114)$. They play important roles in the regulation of cell cycle progression and inhibition of apoptosis (115). Survivin, the smallest (16.5 kDa) member of the family, is overexpressed in many types of cancer, including prostate cancer (116). Survivin prevents apoptosis by directly binding to caspase- 3 and caspase- 7 and blocking their activation (117). Thus, survivin expression is associated with cancer cell malignancy and survival. The activity of survivin can be inhibited by Smac/DIABLO (118), which is released from the 
mitochondria together with cytochrome-c. Due to its rare expression in normal tissues (except embryonic tissues) and overexpression in cancerous tissues, survivin is a promising target for cancer therapy.

To our knowledge, research on the effect of selenium on survivin expression in prostate cancer is still limited to MSeA. MSeA was reported to repress survivin gene expression in PC-3 cells in an oligonucleotide array experiment (58). Later, Chun and co-workers confirmed that MSeA down-regulated survivin protein expression in $\mathrm{PC}-3$ and C4-2 cells by preventing the binding of Sp1 transcription factor to the promoter of survivin (119). Moreover, in combination with tumor necrosis factor-related apoptosis-inducing ligand (TRAIL), a cytotoxic agent that preferentially induces apoptosis, MSeA also induces the translocation of Smac/DIABLO from the mitochondria to the cytosol of DU-145 cells, thereby enhancing the efficacy of TRAIL (120). These results show that the down-regulation of survivin expression is one of the selenium-mediated anticancer mechanisms.

\section{Angiogenesis targets}

Angiogenesis has been proven to play an important role in cancer growth. Although it is strictly regulated by physiological conditions, it has been reported that unregulated angiogenesis occurs under pathological conditions, including cancer (121). Angiogenesis supplies cancerous cells with nutrients and oxygen, removes their waste products and facilitates cancer cell metastasis $(122,123)$. Therefore, the growth of a cancer cell should be inhibited if it is located more than $100 \mu \mathrm{m}$ from a blood vessel (124).

Angiogenesis begins when cancerous cells synthesize and secrete pro-angiogenic factors, such as vascular endothelial growth factor (VEGF), basic fibroblast growth factor (bFGF) and IL-8, among others (125). Secreted proangiogenic factors will activate nearby endothelial cells by binding to specific receptors on the cell surface (121). Upon activation, multiple signaling pathways are activated in endothelial cells that lead to the production of matrix metalloproteinases (MMPs), a special class of degradative enzymes that break down the extracellular matrix support material that fills the spaces between cells (126). Breakdown of this extracellular matrix allows for the migration and growth of endothelial cells $(126,127)$.

Although there are several reports addressing the ability of selenium to decrease cancer cell angiogenesis, research on prostate cancer angiogenesis properties is still limited to MSeA. MSeA treatment of DU-145 cells decreased both cellular and secreted VEGF concentrations in a dose-dependent manner (128). Furthermore, in PC-3 cells, MSeA exposure decreased VEGF and bFGF gene expression (58). Because angiogenesis plays a key role in cancer development, selenium-based antiangiogenic therapy may become an attractive method of preventing cancer cell growth and metastasis.

\section{Conclusions and future challenges}

Prostate cancer has become one of the most common cancers and is one of the leading causes of cancer-related deaths, particularly in developed countries (5). The existence of an agent with multiple anticancer mechanisms, such as selenium, will be beneficial in controlling the development of this disease.
Furthermore, selenium concentrations have been reported to be associated with prostate cancer incidence, leading to the idea of selenium supplementation for prostate cancer prevention. As previously mentioned, recent epidemiological studies that have reported the failure of selenium to lower prostate cancer incidence do not directly discredit the potential of selenium in prostate cancer prevention and therapy because of the type of selenium compound used in those studies.

Although selenium anticancer trials are some of the most successful, its chemical form is critical to its biological activity (1). Methylselenol is believed to be the critical metabolite in selenium chemoprevention (129-131). Since methylselenol is highly reactive, methylselenol precursors such as SeMet and Se-MSC are important both in in vitro and in vivo experiments $(41,52,87)$. SeMet and Se-MSC conversion to methylselenol, however, requires enzymatic conversion by the enzyme $\beta$-lyase, which is 800 times less prevalent in human tissues than in mouse tissues (132). This may explain why the results of SeMet and Se-MSC anticancer studies in humans were not as impressive as in vivo experiments. Although researchers have now turned to other Se compounds such as MSeA, which do not need enzymatic conversion to methylselenol, or selenite, which does not need to be converted to methylselenol for its anticancer properties (25), more substantial research on selenium compound metabolism in human tissues is necessary. Only then will the results of the in vitro, in vivo and human trials be consistent. Understanding the biochemical transformation of each selenium compound in the human body is a critical step in the use of selenium as an option in prostate cancer management.

\section{References}

1. Abdulah R, Miyazaki K, Nakazawa M and Koyama H: Chemical forms of selenium for cancer prevention. J Trace Elem Med Biol 19: 141-150, 2005.

2. Parkin DM, Bray F, Ferlay $J$ and Pisani P: Global cancer statistics, 2002. CA Cancer J Clin 55: 74-108, 2005.

3. Chong P and Rashid P: Can we prevent prostate cancer? Aust Fam Physician 34: 265-267, 2005.

4. Brinkman M, Reulen RC, Kellen E, Buntinx F and Zeegers MP: Are men with low selenium levels at increased risk of prostate cancer? Eur J Cancer 42: 2463-2471, 2006.

5. Jemal A, Siegel R, Ward E, Murray T, Xu J and Thun MJ: Cancer statistics, 2007. CA Cancer J Clin 57: 43-66, 2007.

6. Farkas A, Marcella S and Rhoads GG: Ethnic and racial differences in prostate cancer incidence and mortality. Ethn Dis 10: 69-75, 2000.

7. Brawley OW, Jani AB and Master V: Prostate cancer and race Curr Probl Cancer 31: 211-225, 2007.

8. Bono AV: The global state of prostate cancer: epidemiology and screening in the second millennium. BJU Int 94 (Suppl 3): S1-S2, 2004.

9. Konishi N, Shimada K, Ishida E and Nakamura M: Molecular pathology of prostate cancer. Pathol Int 55: 531-539, 2005.

10. Sim HG and Cheng CW: Changing demography of prostate cancer in Asia. Eur J Cancer 41: 834-845, 2005.

11. Clark LC, Combs GF Jr, Turnbull BW, et al: Effects of selenium supplementation for cancer prevention in patients with carcinoma of the skin. A randomized controlled trial. Nutritional Prevention of Cancer Study Group. JAMA 276: 1957-1963, 1996.

12. Kim J, Sun P, Lam YW, et al: Changes in serum proteomic patterns by presurgical alpha-tocopherol and L-selenomethionine supplementation in prostate cancer. Cancer Epidemiol Biomarkers Prev 14: 1697-1702, 2005.

13. Sabichi AL, Lee JJ, Taylor RJ, et al: Selenium accumulation in prostate tissue during a randomized, controlled short-term trial of 1-selenomethionine: a Southwest Oncology Group Study. Clin Cancer Res 12: 2178-2184, 2006. 
14. Brooks JD, Metter EJ, Chan DW, et al: Plasma selenium level before diagnosis and the risk of prostate cancer development. J Urol 166: 2034-2038, 2001

15. Vogt TM, Ziegler RG, Graubard BI, et al: Serum selenium and risk of prostate cancer in U.S. blacks and whites. Int J Cancer 103: 664-670, 2003.

16. Ozmen H, Erulas FA, Karatas F, Cukurovali A and Yalcin O: Comparison of the concentration of trace metals $(\mathrm{Ni}, \mathrm{Zn}, \mathrm{Co}, \mathrm{Cu}$ and Se), Fe, vitamins $\mathrm{A}, \mathrm{C}$ and $\mathrm{E}$, and lipid peroxidation in patients with prostate cancer. Clin Chem Lab Med 44: 175-179, 2006.

17. Yoshizawa K, Willett WC, Morris SJ, et al: Study of prediagnostic selenium level in toenails and the risk of advanced prostate cancer. J Natl Cancer Inst 90: 1219-1224, 1998

18. van den Brandt PA, Zeegers MP, Bode P and Goldbohm RA: Toenail selenium levels and the subsequent risk of prostate cancer: a prospective cohort study. Cancer Epidemiol Biomarkers Prev 12: 866-871, 2003.

19. Garland M, Morris JS, Rosner BA, et al: Toenail trace element levels as biomarkers: reproducibility over a 6-year period. Cancer Epidemiol Biomarkers Prev 2: 493-497, 1993.

20. Longnecker MP, Stram DO, Taylor PR, et al: Use of selenium concentration in whole blood, serum, toenails, or urine as a surrogate measure of selenium intake. Epidemiology 7: 384-390, 1996.

21. Allen NE, Morris JS, Ngwenyama RA and Key TJ: A casecontrol study of selenium in nails and prostate cancer risk in British men. Br J Cancer 90: 1392-1396, 2004.

22. Peters U, Foster CB, Chatterjee N, et al: Serum selenium and risk of prostate cancer - a nested case-control study. Am J Clin Nutr 85: 209-217, 2007.

23. Peters U, Littman AJ, Kristal AR, Patterson RE, Potter JD and White E: Vitamin E and selenium supplementation and risk of prostate cancer in the Vitamins and Lifestyle (VITAL) Study cohort. Cancer Causes Control 19: 75-87, 2008.

24. Lippman SM, Klein EA, Goodman PJ, et al: Effect of selenium and vitamin $E$ on risk of prostate cancer and other cancers: the Selenium and Vitamin E Cancer Prevention Trial (SELECT). JAMA 301: 39-51, 2009.

25. Drake EN: Cancer chemoprevention: selenium as a prooxidant, not an antioxidant. Med Hypotheses 67: 318-322, 2006.

26. Larsen EH, Hansen M, Paulin H, Moesgaard S, Reid M and Rayman M: Speciation and bioavailability of selenium in yeastbased intervention agents used in cancer chemoprevention studies. J AOAC Int 87: 225-232, 2004.

27. El-Bayoumy K: The negative results of the SELECT study do not necessarily discredit the selenium-cancer prevention hypothesis. Nutr Cancer 61: 285-286, 2009.

28. Dagnelie PC, Schuurman AG, Goldbohm RA and Van den Brandt PA: Diet, anthropometric measures and prostate cancer risk: a review of prospective cohort and intervention studies. BJU Int 93: 1139-1150, 2004

29. Etminan M, FitzGerald JM, Gleave $M$ and Chambers K: Intake of selenium in the prevention of prostate cancer: a systematic review and meta-analysis. Cancer Causes Control 16: 1125-1131, 2005.

30. Lamb DJ, Weigel NL and Marcelli M: Androgen receptors and their biology. Vitam Horm 62: 199-230, 2001.

31. Dehm SM and Tindall DJ: Molecular regulation of androgen action in prostate cancer. J Cell Biochem 99: 333-344, 2006.

32. Sommer A and Haendler B: Androgen receptor and prostate cancer: molecular aspects and gene expression profiling. Curr Opin Drug Discov Devel 6: 702-711, 2003.

33. Hobisch A, Eder IE, Putz T, et al: Interleukin-6 regulates prostatespecific protein expression in prostate carcinoma cells by acti-vation of the androgen receptor. Cancer Res 58: 4640-4645, 1998.

34. Godoy-Tundidor S, Hobisch A, Pfeil K, Bartsch G and Culig Z: Acquisition of agonistic properties of nonsteroidal antiandrogens after treatment with oncostatin $\mathrm{M}$ in prostate cancer cells. Clin Cancer Res 8: 2356-2361, 2002.

35. Cho SD, Jiang C, Malewicz B, et al: Methyl selenium metabolites decrease prostate-specific antigen expression by inducing protein degradation and suppressing androgen-stimulated transcription. Mol Cancer Ther 3: 605-611, 2004.

36. Zhao H, Whitfield ML, Xu T, Botstein D and Brooks JD: Diverse effects of methylseleninic acid on the transcriptional program of human prostate cancer cells. Mol Biol Cell 15: 506-519, 2004.

37. Chun JY, Nadiminty N, Lee SO, Onate SA, Lou W and Gao AC: Mechanisms of selenium down-regulation of androgen receptor signaling in prostate cancer. Mol Cancer Ther 5: 913-918, 2006.
38. Dong Y, Lee SO, Zhang H, Marshall J, Gao AC and Ip C: Prostate specific antigen expression is down-regulated by selenium through disruption of androgen receptor signaling. Cancer Res 64: 19-22, 2004

39. Husbeck B, Bhattacharyya RS, Feldman D and Knox SJ: Inhibition of androgen receptor signaling by selenite and methylseleninic acid in prostate cancer cells: two distinct mechanisms of action. Mol Cancer Ther 5: 2078-2085, 2006.

40. Morris JD, Pramanik R, Zhang X, et al: Selenium- or quercetininduced retardation of DNA synthesis in primary prostate cells occurs in the presence of a concomitant reduction in androgenreceptor activity. Cancer Lett 239: 111-122, 2006.

41. Lee SO, Yeon Chun J, Nadiminty N, et al: Monomethylated selenium inhibits growth of LNCaP human prostate cancer xenograft accompanied by a decrease in the expression of androgen receptor and prostate-specific antigen (PSA). Prostate 66: 1070-1075, 2006

42. Gazi MH, Gong A, Donkena KV and Young CY: Sodium selenite inhibits interleukin-6-mediated androgen receptor activation in prostate cancer cells via upregulation of c-Jun. Clin Chim Acta 380: 145-150, 2007.

43. Gennigens C, Menetrier-Caux C and Droz JP: Insulin-like growth factor (IGF) family and prostate cancer. Crit Rev Oncol Hematol 58: 124-145, 2006.

44. Sachdev D and Yee D: Disrupting insulin-like growth factor signaling as a potential cancer therapy. Mol Cancer Ther 6: 1-12, 2007.

45. Liao Y, Abel U, Grobholz R, et al: Up-regulation of insulin-like growth factor axis components in human primary prostate cancer correlates with tumor grade. Hum Pathol 36: 1186-1196, 2005.

46. Grimberg A: Mechanisms by which IGF-I may promote cancer. Cancer Biol Ther 2: 630-635, 2003.

47. MacDonald RG, Pfeffer SR, Coussens L, et al: A single receptor binds both insulin-like growth factor II and mannose-6phosphate. Science 239: 1134-1137, 1988.

48. Khandwala HM, McCutcheon IE, Flyvbjerg A and Friend KE: The effects of insulin-like growth factors on tumorigenesis and neoplastic growth. Endocr Rev 21: 215-244, 2000.

49. Chan JM, Stampfer MJ, Giovannucci E, et al: Plasma insulinlike growth factor-I and prostate cancer risk: a prospective study. Science 279: 563-566, 1998.

50. Chokkalingam AP, Pollak M, Fillmore CM, et al: Insulin-like growth factors and prostate cancer: a population-based casecontrol study in China. Cancer Epidemiol Biomarkers Prev 10: 421-427, 2001.

51. Schlicht M, Matysiak B, Brodzeller T, et al: Cross-species global and subset gene expression profiling identifies genes involved in prostate cancer response to selenium. BMC Genomics 5: 58, 2004.

52. Zhao H and Brooks JD: Selenomethionine induced transcriptional programs in human prostate cancer cells. J Urol 177: 743-750, 2007.

53. Konig JE, Senge T, Allhoff EP and Konig W: Analysis of the inflammatory network in benign prostate hyperplasia and prostate cancer. Prostate 58: 121-129, 2004.

54. Zheng SL, Augustsson-Balter K, Chang B, et al: Sequence variants of toll-like receptor 4 are associated with prostate cancer risk: results from the cancer prostate in Sweden study. Cancer Res 64: 2918-2922, 2004.

55. Chen YC, Giovannucci E, Lazarus R, Kraft P, Ketkar S and Hunter DJ: Sequence variants of Toll-like receptor 4 and susceptibility to prostate cancer. Cancer Res 65: 11771-11778, 2005.

56. Sun J, Wiklund F, Zheng SL, et al: Sequence variants in Toll-like receptor gene cluster (TLR6-TLR1-TLR10) and prostate cancer risk. J Natl Cancer Inst 97: 525-532, 2005.

57. Singh RP and Agarwal R: Mechanisms of action of novel agents for prostate cancer chemoprevention. Endocr Relat Cancer 13: 751-778, 2006

58. Dong Y, Zhang H, Hawthorn L, Ganther HE and Ip C: Delineation of the molecular basis for selenium-induced growth arrest in human prostate cancer cells by oligonucleotide array. Cancer Res 63: 52-59, 2003

59. Aliprantis AO, Yang RB, Weiss DS, Godowski P and Zychlinsky A: The apoptotic signaling pathway activated by Toll-like receptor- 2 . EMBO J 19: 3325-3336, 2000.

60. Cantley LC and Neel BG: New insights into tumor suppression: PTEN suppresses tumor formation by restraining the phosphoinositide 3-kinase/AKT pathway. Proc Natl Acad Sci USA 96: 4240-4245, 1999. 
61. Wu Y, Zu K, Warren MA, Wallace PK and Ip C: Delineating the mechanism by which selenium deactivates Akt in prostate cancer cells. Mol Cancer Ther 5: 246-252, 2006.

62. Berggren M, Sittadjody S, Song Z, Samira JL, Burd R and Meuillet EJ: Sodium selenite increases the activity of the tumor suppressor protein, PTEN, in DU-145 prostate cancer cells. Nutr Cancer 61: 322-331, 2009.

63. Jiang C, Wang Z, Ganther H and Lu J: Distinct effects of methyl-seleninic acid versus selenite on apoptosis, cell cycle, and protein kinase pathways in DU145 human prostate cancer cells. Mol Cancer Ther 1: 1059-1066, 2002.

64. Wang Z, Jiang C and Lu J: Induction of caspase-mediated apoptosis and cell-cycle G1 arrest by selenium metabolite methylselenol. Mol Carcinog 34: 113-120, 2002.

65. Abdulah R, Faried A, Kobayashi K, et al: Selenium enrichment of broccoli sprout extract increases chemosensitivity and apoptosis of LNCaP prostate cancer cells. BMC Cancer 9: 414, 2009.

66. Lee MH and Yang HY: Negative regulators of cyclin-dependent kinases and their roles in cancers. Cell Mol Life Sci 58: 1907$1922,2001$.

67. van den Heuvel S: Cell-cycle regulation. WormBook 1-16, 2005.

68. Diehl JA: Cycling to cancer with cyclin D1. Cancer Biol Ther 1: 226-231, 2002.

69. Boonstra J: Progression through the G1-phase of the on-going cell cycle. J Cell Biochem 90: 244-252, 2003.

70. Su TT and Stumpff J: Promiscuity rules? The dispensability of cyclin E and Cdk2. Sci STKE 2004: pe11, 2004.

71. Hwang HC and Clurman BE: Cyclin E in normal and neoplastic cell cycles. Oncogene 24: 2776-2786, 2005.

72. Stein GS, van Wijnen AJ, Stein JL, et al: An architectural perspective of cell-cycle control at the G1/S phase cell-cycle transition. J Cell Physiol 209: 706-710, 2006.

73. Goldstone S, Pavey S, Forrest A, Sinnamon J and Gabrielli B: Cdc25-dependent activation of cyclin A/cdk2 is blocked in G2 phase arrested cells independently of ATM/ATR. Oncogene 20: 921-932, 2001.

74. Maddika S, Ande SR, Wiechec E, Hansen LL, Wesselborg S and Los M: Akt-mediated phosphorylation of CDK2 regulates its dual role in cell cycle progression and apoptosis. J Cell Sci 121: 979-988, 2008.

75. De Boer L, Oakes V, Beamish H, et al: Cyclin A/cdk2 coordinates centrosomal and nuclear mitotic events. Oncogene 27: 4261-4268, 2008.

76. O'Farrell PH: Triggering the all-or-nothing switch into mitosis. Trends Cell Biol 11: 512-519, 2001.

77. Porter LA and Donoghue DJ: Cyclin B1 and CDK1: nuclear localization and upstream regulators. Prog Cell Cycle Res 5: 335-347, 2003.

78. Dai Y and Grant S: Cyclin-dependent kinase inhibitors. Curr Opin Pharmacol 3: 362-370, 2003.

79. Xiong Y, Hannon GJ, Zhang H, Casso D, Kobayashi R and Beach D: p21 is a universal inhibitor of cyclin kinases. Nature 366: 701-704, 1993.

80. Polyak K, Lee MH, Erdjument-Bromage H, et al: Cloning of p27Kip1, a cyclin-dependent kinase inhibitor and a potential mediator of extracellular antimitogenic signals. Cell 78: 59-66, 1994.

81. Ortega S, Malumbres M and Barbacid M: Cyclin D-dependent kinases, INK4 inhibitors and cancer. Biochim Biophys Acta 1602: 73-87, 2002

82. Canepa ET, Scassa ME, Ceruti JM, et al: INK4 proteins, a family of mammalian CDK inhibitors with novel biological functions. IUBMB Life 59: 419-426, 2007.

83. Zhong W and Oberley TD: Redox-mediated effects of selenium on apoptosis and cell cycle in the LNCaP human prostate cancer cell line. Cancer Res 61: 7071-7078, 2001.

84. Menter DG, Sabichi AL and Lippman SM: Selenium effects on prostate cell growth. Cancer Epidemiol Biomarkers Prev 9: 1171-1182, 2000.

85. Ni J, Chen M, Zhang Y, Li R, Huang J and Yeh S: Vitamin E succinate inhibits human prostate cancer cell growth via modulating cell cycle regulatory machinery. Biochem Biophys Res Commun 300: 357-363, 2003.

86. Venkateswaran V, Klotz LH and Fleshner NE: Selenium modulation of cell proliferation and cell cycle biomarkers in human prostate carcinoma cell lines. Cancer Res 62: 2540-2545, 2002.

87. Zhao R, Domann FE and Zhong W: Apoptosis induced by selenomethionine and methioninase is superoxide mediated and p53 dependent in human prostate cancer cells. Mol Cancer Ther 5: $3275-3284,2006$.
88. Harbour JW and Dean DC: Rb function in cell-cycle regulation and apoptosis. Nat Cell Biol 2: E65-E67, 2000.

89. Taya Y: RB kinases and RB-binding proteins: new points of view. Trends Biochem Sci 22: 14-17, 1997.

90. Du W and Pogoriler J: Retinoblastoma family genes. Oncogene 25: 5190-5200, 2006

91. Genovese C, Trani D, Caputi M and Claudio PP: Cell cycle control and beyond: emerging roles for the retinoblastoma gene family. Oncogene 25: 5201-5209, 2006.

92. Cam H and Dynlacht BD: Emerging roles for E2F: beyond the G1/S transition and DNA replication. Cancer Cell 3: 311-316, 2003.

93. Knudsen ES and Knudsen KE: Retinoblastoma tumor suppressor: where cancer meets the cell cycle. Exp Biol Med (Maywood) 231: 1271-1281, 2006.

94. Mittnacht S: Control of pRB phosphorylation. Curr Opin Genet Dev 8: 21-27, 1998

95. Mittnacht $\mathrm{S}$ : The retinoblastoma protein-from bench to bedside. Eur J Cell Biol 84: 97-107, 2005.

96. Chau BN and Wang JY: Coordinated regulation of life and death by RB. Nat Rev Cancer 3: 130-138, 2003.

97. Sun A, Bagella L, Tutton S, Romano G and Giordano A: From G0 to S phase: a view of the roles played by the retinoblastoma $(\mathrm{Rb})$ family members in the Rb-E2F pathway. J Cell Biochem 102: 1400-1404, 2007.

98. Shen HM and Tergaonkar V: NFkappaB signaling in carcinogenesis and as a potential molecular target for cancer therapy. Apoptosis 14: 348-363, 2009.

99. Huang S, Pettaway CA, Uehara H, Bucana CD and Fidler IJ: Blockade of NF-kappaB activity in human prostate cancer cells is associated with suppression of angiogenesis, invasion, and metastasis. Oncogene 20: 4188-4197, 2001.

100. Suh J and Rabson AB: NF-kappaB activation in human prostate cancer: important mediator or epiphenomenon? J Cell Biochem 91: 100-117, 2004

101. Jin RJ, Lho Y, Connelly L, et al: The nuclear factor-kappaB pathway controls the progression of prostate cancer to androgenindependent growth. Cancer Res 68: 6762-6769, 2008.

102. Gasparian AV, Yao YJ, Lu J, et al: Selenium compounds inhibit I kappa B kinase (IKK) and nuclear factor-kappa B (NF-kappa B) in prostate cancer cells. Mol Cancer Ther 1: 1079-1087, 2002.

103. Christensen MJ, Nartey ET, Hada AL, Legg RL and Barzee BR: High selenium reduces NF-kappaB-regulated gene expression in uninduced human prostate cancer cells. Nutr Cancer 58: 197-204, 2007.

104. Kang MH and Reynolds CP: Bcl-2 inhibitors: targeting mitochondrial apoptotic pathways in cancer therapy. Clin Cancer Res 15: 1126-1132, 2009.

105. Bruckheimer EM and Kyprianou N: Apoptosis in prostate carcinogenesis. A growth regulator and a therapeutic target. Cell Tissue Res 301: 153-162, 2000.

106. Brunelle JK and Letai A: Control of mitochondrial apoptosis by the Bcl-2 family. J Cell Sci 122: 437-441, 2009.

107. Hu H, Jiang C, Schuster T, Li GX, Daniel PT and Lu J: Inorganic selenium sensitizes prostate cancer cells to TRAIL-induced apoptosis through superoxide/p53/Bax-mediated activation of mitochondrial pathway. Mol Cancer Ther 5: 1873-1882, 2006.

108. Husbeck B, Peehl DM and Knox SJ: Redox modulation of human prostate carcinoma cells by selenite increases radiationinduced cell killing. Free Radic Biol Med 38: 50-57, 2005.

109. Husbeck B, Nonn L, Peehl DM and Knox SJ: Tumor-selective killing by selenite in patient-matched pairs of normal and malignant prostate cells. Prostate 66: 218-225, 2006.

110. Zhao R, Xiang N, Domann FE and Zhong W: Expression of p53 enhances selenite-induced superoxide production and apoptosis in human prostate cancer cells. Cancer Res 66: 2296-2304, 2006.

111. Zhao R, Xiang N, Domann FE and Zhong W: Effects of selenite and genistein on G2/M cell cycle arrest and apoptosis in human prostate cancer cells. Nutr Cancer 61: 397-407, 2009.

112. Reagan-Shaw S, Nihal M, Ahsan H, Mukhtar H and Ahmad N: Combination of vitamin $\mathrm{E}$ and selenium causes an induction of apoptosis of human prostate cancer cells by enhancing Bax/ Bcl-2 ratio. Prostate 68: 1624-1634, 2008.

113. Deveraux QL, Stennicke HR, Salvesen GS and Reed JC: Endogenous inhibitors of caspases. J Clin Immunol 19: 388-398, 1999.

114. Salvesen GS and Duckett CS: IAP proteins: blocking the road to death's door. Nat Rev Mol Cell Biol 3: 401-410, 2002. 
115. Yamamoto $\mathrm{H}, \mathrm{Ngan} \mathrm{CY}$ and Monden M: Cancer cells survive with survivin. Cancer Sci 99: 1709-1714, 2008.

116. Kishi H, Igawa M, Kikuno N, Yoshino T, Urakami S and Shiina H: Expression of the survivin gene in prostate cancer: correlation with clinicopathological characteristics, proliferative activity and apoptosis. J Urol 171: 1855-1860, 2004.

117. Shin S, Sung BJ, Cho YS, et al: An anti-apoptotic protein human survivin is a direct inhibitor of caspase-3 and -7. Biochemistry 40: 1117-1123, 2001.

118. Sun C, Nettesheim D, Liu Z and Olejniczak ET: Solution structure of human survivin and its binding interface with Smac/Diablo. Biochemistry 44: 11-17, 2005.

119. Chun JY, Hu Y, Pinder E, Wu J, Li F and Gao AC: Selenium inhibition of survivin expression by preventing Spl binding to its promoter. Mol Cancer Ther 6: 2572-2580, 2007.

120. Yamaguchi K, Uzzo RG, Pimkina J, et al: Methylseleninic acid sensitizes prostate cancer cells to TRAIL-mediated apoptosis. Oncogene 24: 5868-5877, 2005.

121. Kerbel RS: Tumor angiogenesis. N Engl J Med 358: 2039-2049, 2008.

122. Duffy MJ, McGowan PM and Gallagher WM: Cancer invasion and metastasis: changing views. J Pathol 214: 283-293, 2008.

123. Mauriz JL and Gonzalez-Gallego J: Antiangiogenic drugs: current knowledge and new approaches to cancer therapy. J Pharm Sci 97: 4129-4154, 2008
124. Folkman J: Tumor angiogenesis: therapeutic implications. N Engl J Med 285: 1182-1186, 1971

125. Bergers $\mathrm{G}$ and Benjamin LE: Tumorigenesis and the angiogenic switch. Nat Rev Cancer 3: 401-410, 2003.

126. Overall CM and Lopez-Otin C: Strategies for MMP inhibition in cancer: innovations for the post-trial era. Nat Rev Cancer 2: 657-672, 2002.

127. Freije JM, Balbin M, Pendas AM, Sanchez LM, Puente XS and Lopez-Otin C: Matrix metalloproteinases and tumor progression. Adv Exp Med Biol 532: 91-107, 2003

128. Jiang C, Ganther H and Lu J: Monomethyl selenium-specific inhibition of MMP-2 and VEGF expression: implications for angiogenic switch regulation. Mol Carcinog 29: 236-250, 2000.

129. Ip C: Lessons from basic research in selenium and cancer prevention. J Nutr 128: 1845-1854, 1998.

130. Ip C, Dong Y and Ganther HE: New concepts in selenium chemoprevention. Cancer Metastasis Rev 21: 281-289, 2002.

131. Whanger PD: Selenium and its relationship to cancer: an update. Br J Nutr 91: 11-28, 2004.

132. Rooseboom M, Vermeulen NP, Andreadou I and Commandeur JN Evaluation of the kinetics of beta-elimination reactions of selenocysteine Se-conjugates in human renal cytosol: possible implications for the use as kidney selective prodrugs. J Pharmacol Exp Ther 294: 762-769, 2000. 